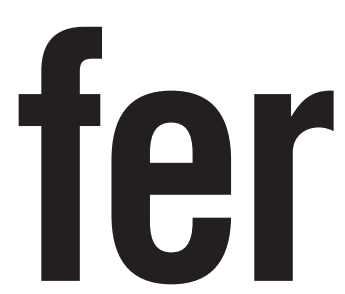

\section{Family and}

\section{Environment}

\section{Research}

Received: November 25, 2014

Revised: December 26, 2014

Accepted: December 29, 2014

Corresponding Author:

\section{Mi Young Sung}

Department of Child Studies,

Seokyeong University, 124 Seokyeong-

ro, Seongbuk-gu, Seoul 136-704,

Korea

Tel: +82-2-940-7554

Fax: +82-2-940-7554

E-mail: minieming@empas.com

\section{유아의 한국어 어휘학습용 어플리케이션 분석: 태블릿 PC 어플리케이션을 중심으로}

성미영

서경대학교 아동학과

\author{
Analysis of Applications for Preschoolers' Korean Vocabulary Learning: Focusing on \\ Tablet PC Applications \\ Mi Young Sung \\ Department of Child Studies, Seokyeong University, Seoul, Korea
}

Abstract

This study evaluated the content of Korean vocabulary learning applications with a focus on tablet PC applications. We analyzed 51 Korean vocabulary learning applications. The instruments in this study were developed based on Yoo et al. (2012)' Vocabulary Learning Game Application Evaluation Criteria and Hyun et al. (2013)' Educational Application Evaluation Criteria. Data were analyzed using a t-test and one-way analysis of variance. The main results are as follows. First, each criteria's score was fairly good; the ease of use had the highest scores and the amusement had the lowest scores. Second, there was a significant difference in the interaction by vocabulary teaching approach. Applications based on a whole language-teaching method had higher scores than applications based on a phonics instructional teaching method inducing more operation and with immediate feedback. Third, there was significant difference in the sum of score and each criteria of developmental appropriateness, educational values, amusement, function and interaction by type of learning. Applications of combining type had higher scores in every criteria except for ease of use than applications of description type. These findings provide a preliminary evidence that the systematic Korean vocabulary learning application facilitates preschoolers' vocabulary learning.

Keywords

applications, vocabulary learning, tablet PC

\section{서론}

2010년 4월 미국에서 처음으로 아이패드(iPad)가 출시된 이후 태블릿 PC는 스마트폰과 함께 중요 한 글로벌 IT시장으로 자리매김하고 있다. 실제 태블릿 PC는 2010년 1,716만대의 판매량을 기록하 였는데, 2011년에는 무려 400\% 성장한 6,978만대를 판매하였다. 2012년에는 1억대를 돌파하였으 며, 2015년에는 연간 판매량이 3억대에 근접하는 높은 성장세를 보일 것으로 전망하고 있다[15]. 이 처럼 태블릿 $\mathrm{PC}$ 의 높은 성장세로 인해 실생활에서 성인뿐만 아니라 유아도 이를 활용할 기회가 증가 하였다. 태블릿 PC를 이용한 학습은 스마트러닝(smart learning)에 해당하는데, 모바일기기, 스마트 폰, 태블릿 PC 등의 새로운 디바이스를 교육에 활용하려는 시도가 활발하게 진행되고 있다[11]. 스마 트러닝은 학습자-학습자, 학습자-교수자, 학습자-콘텐츠 간의 소통, 협력, 참여, 개방, 공유 기능이 가능하도록 하는 information and communication technology (ICT) 기술을 활용함으로써, 수평적, 쌍방향적, 참여적, 상호작용적인 방식으로 학습의 효과를 증대시킨다는 장점이 있다[10, 23]. 온라인 
수업의 활성화를 통해 장소에 구애받지 않고 교육이 가능하며, 시 간적 제약조건도 없어서 클라우드 교육서비스 등을 활용한다면 언 제나 원할 때 학습이 가능하다. 따라서 유아를 위한 한국어 어휘학 습에서도 스마트러닝의 차원에서 교수매체로 태블릿 $\mathrm{PC}$ 용 어플리 케이션을 이용하는 접근이 필요하다.

태블릿 $\mathrm{PC}$ 란 소형 - 휴대형 컴퓨터의 디스플레이가 터치스크린 으로 구성되어 있어, 키보드나 마우스 대신 손가락 또는 터치펜으 로 조작할 수 있는 기기를 의미한다. 태블릿 $\mathrm{PC}$ 의 성능은 휴대용 기기에 적합하게 가볍고 휴대성이 좋으며, 스마트폰보다 더 큰 화 면으로 말미암아, 동영상, 음악, 사진 등 미디어 콘텐츠 활용도가 극대화될 수 있다. 최근 태블릿 $\mathrm{PC}$ 의 보급이 급증하면서 수평적, 참여적, 상호작용적인 교육방식의 효과가 높아지고 있으므로 태블 릿 $\mathrm{PC}$ 를 유아의 한국어 어휘학습에 적극 활용한다면 좋은 효과를 거둘 것으로 예측된다[2, 24]. 이처럼 유아의 한국어 어휘학습에 있어서 태블릿 $\mathrm{PC}$ 어플리케이션을 이용할 경우 그 효과성을 고려 해 볼 때 기존에 개발되어 활용되고 있는 한국어 어휘학습용 어플 리케이션의 현황을 우선적으로 분석함으로써 이를 토대로 유아의 발달수준에 적합하며 한국어 어휘학습을 촉진시킬 수 있는 어플리 케이션 개발의 필요성을 확인해 보고자 하였다.

지금까지 진행된 어플리케이션의 분석에 관한 선행연구들의 경 우 어플리케이션의 사용기기 측면에서는 스마트폰용 위주로[7-9, 17], 또는 스마트폰용과 태블릿 PC용 어플리케이션을 통합하여[6] 분석하였다. 예를 들어, $\operatorname{Kim}$ 등[9]의 연구에서는 아이폰 웹스토어 및 안드로이드 마켓의 교육 카테고리에 탑재되어 있는 어플리케이 션 중 61 개의 유아용 어플리케이션을 선정하여 학습유형별 콘텐 츠 유형, 인지부하원리, 멀티미디어 설계원리에 기반을 둔 분석기 준으로 어플리케이션을 분석하였다. 그 결과 스마트폰의 성능을 최대한 활용하고, 멀티미디어 설계원리를 준수하는 어플리케이션 개발의 필요성을 제기하였다.

어플리케이션의 사용자 측면에서는 성인용 $[12,20]$ 또는 유아 용 어플리케이션 $[9,13]$ 으로 구분하여 분석하였는데 유아가 아닌 20,30 대 성인을 대상으로 이들의 학습자 요구를 분석하여 스마트 폰 어휘학습용 어플리케이션을 구현한 연구도 실시되었다[12]. 또 한 어플리케이션의 내용 측면에서는 특정 내용 영역에만 한정시키 지 않고 전반적인 어플리케이션을 분석하거나, 유아교육용 어플 리케이션[27], 유아용 한글학습[6]이나 외국어[3], 특히 영어학습 에 관한 어플리케이션을 분석한 연구들이 대부분이었다. 구체적으 로, 유아교육용 어플리케이션의 내용과 사용자 인터페이스 상호작 용을 분석한 연구[26]에 의하면, 각 평가영역별 점수는 전반적으 로 높은 것으로 나타났으며, 교육성 영역의 경우에는 놀이형 어플
리케이션과 감상형 어플리케이션 간에 차이가 있는 것으로 나타났 다. 이 연구의 경우에는 학습유형에 따라 유아교육용 어플리케이 션의 평가 점수에 차이가 있음을 보여주었으나, 한글학습 등의 한 정된 어플리케이션에 대한 학습유형별 차이에 대해서는 살펴보지 않았다. 발음중심 또는 총체적 접근방법 중 어떤 언어 교수방법에 기반을 두고 있느냐에 따라서도 따라서 한국어 어휘학습용 어플리 케이션의 내용분석에 차이가 있을 것으로 예상되므로 이 연구에서 는 학습유형별 차이와 더불어 언어 교수방법에 따라 어플리케이션 내용분석에 차이가 있는지를 살펴보고자 하였다.

유아가 문자언어를 학습하는데 있어 사용되는 교수방법은 다양 하다. 그 중 일반적으로 한국어 어휘학습용 어플리케이션에 사용된 교수방법으로 발음중심 언어 교수방법과 총체적 언어 교수방법 $[5$, 18]을 들 수 있다. 발음중심 언어 교수방법은 읽기, 쓰기에 필요한 기초적인 지식과 기술을 체계적으로 가르치는 교수방법으로 문자해 독을 위한 자모체계, 글자와 말소리 대응, 철자법 등의 학습을 강조 한다. 이와 달리 총체적 언어 교수방법은 기술과 지식 위주의 형식 적 언어지도가 아니라 맥락에서의 의미를 강조하여 의사소통과 의 미 이해를 목적으로 하는 언어 교수방법을 의미한다. 따라서 본 연 구에서는 자음과 모음의 연결, 글자와 말소리의 대응, 철자법을 위 주로 한 어플리케이션의 경우 발음중심 언어 교수방법으로 구분하 였고, 추상적인 낱자가 아니라 구체적인 단어의 의미를 중심으로 한 어플리케이션의 경우에는 총체적 언어 교수방법으로 구분하였다. 어플리케이션 분석에 사용되는 학습유형은 연구자에 따라 상이한 데, 이 연구의 한국어 어휘학습용 어플리케이션에 사용된 학습유형 은 Kim 등[9], Lee [14], Yoo 등[26]의 학습유형 분류기준에 기초하 여 어휘학습용 어플리케이션에 부적합한 학습유형 범주를 제외하고 서술형(사전, 도감, 레시피 등), 놀이형(게임, 만들기, 꾸미기 등), 문 제풀이형(질문에 적절한 답 찾기 등), 복합형(서술형, 놀이형, 문제 풀이형 중 둘 이상의 유형이 혼합된 유형)으로 구분하였다.

어플리케이션 분석 관련 선행연구 중 일부 연구[6]에서는 유아 를 대상으로 한 언어학습용 어플리케이션을 분석하였으나, 이 경 우에는 단어게임에만 한정하여 어플리케이션을 분석하였다. 따라 서 유아를 대상으로 개발된 어휘학습용 어플리케이션에 초점을 두 고 교수방법이나 학습유형에 따라 그 내용을 분석한 연구는 아직 실시되지 않았다. 언어 교수방법의 경우 전통적인 발음중심 접근 법에 기반을 둔 어플리케이션인지 아니면 총체적 접근법에 기반을 둔 접근법인지에 따라 어플리케이션 평가영역에서 다른 양상이 나 타날 것으로 예상된다. 따라서 이 연구에서는 유아의 어휘학습을 돕는 어플리케이션의 실태를 교수방법이나 학습유형의 측면에서 비교 분석하여 장단점 등을 파악함으로써 유아의 한국어 어휘학습 
에 적합한 어플리케이션의 기본 특성을 파악하고자 하였다.

나이 어린 유아의 언어지체, 특히 어휘발달의 지체는 학령기의 학업지체로 이어지고, 이러한 언어능력의 부족은 초등학교 입학 이 후 학교생활에 적응하는데 있어서 어려움을 초래한다. 어휘발달에 문제가 있는 일반가정 유아나 다문화가정 유아를 대상으로 한국어 어휘능력을 향상시키는데 도움을 줄 수 있는 방법은 다양하나, 최 근 스마트 기기의 발달을 고려할 때 한국어 어휘학습용 어플리케이 션을 활용하는 것이 효과적일 것으로 예측된다. 그런데 유아의 스 마트기기 중독에 관한 실태조사 결과는 태블릿 $\mathrm{PC}$ 를 활용하는 방 법이 유아의 발달에 부정적인 영향을 미칠 수 있으며, 이를 통한 어 휘학습에 대해 부정적인 시각을 가지게 한다. 그러나 본 연구에서 살펴보고자 하는 측면은 전적으로 태블릿 $\mathrm{PC}$ 를 활용하여 유아의 어휘발달을 촉진시키자는 것이 아니라 어휘학습의 보조적 도구로 서의 태블릿 $\mathrm{PC}$ 의 활용가능성을 확인하는 것이다. 어휘학습 어플 리케이션의 교수방법과 학습유형에 따라 어플리케이션의 평가요소 별 점수에 차이가 나타날 수 있으므로 교수방법과 학습유형에 따라 어플리케이션을 분석해봄으로써 유아의 어휘학습에 보다 적합한 어플리케이션의 특징을 파악하고자 한다. 이러한 분석결과를 토대 로 유아의 어휘학습을 보조하기 위한 어플리케이션의 효과성을 확 인하고자 한다. 기존에 개발된 태블릿 $\mathrm{PC}$ 용 어휘학습 어플리케이 션이 유아의 어휘학습을 보조하는 효과적인 도구인지를 살펴봄으 로써 태블릿 $\mathrm{PC}$ 용 어플리케이션이 부정적 측면만이 아닌 긍정적인 학습의 도구로 활용될 수 있음을 확인하고자 하였다. 따라서 이 연 구에서는 기존에 개발된 한국어 어휘학습용 어플리케이션의 내용 과 특성을 분석하여 그 효과성을 확인하고자 하였다.

이상의 연구목적에 따라 다음과 같은 연구문제를 선정하였다. 연구문제 1. 유아 대상 한국어 어휘학습용 어플리케이션 내용의 일반적 경향은 어떠한가?

연구문제 2. 유아 대상 한국어 어휘학습용 어플리케이션 내용은 교수방법에 따라 유의한 차이가 있는가?

연구문제 3. 유아 대상 한국어 어휘학습용 어플리케이션 내용은

학습유형에 따라 유의한 차이가 있는가?

\section{연구방법}

\section{1. 연구대상}

본 연구에서는 태블릿 $\mathrm{PC}$ 어플리케이션 판매처인 App Store 와 Play Store에서 2014년 6월 현재 판매되고 있는 어플리케이션 을 '한글' 키워드로 검색하여 각각 다운로드 횟수가 많은 150 위까
지의 어플리케이션 중 유아를 대상으로 한 어플리케이션만을 분석 대상으로 선정하였다. 안드로이드와 애플을 운영체제로 하는 어 플리케이션 중 두 가지 운영체제를 공유하는 어플리케이션이 많으 므로 중복되는 어플리케이션은 하나의 어플리케이션으로 간주하 고, 동일한 회사에서 동일한 명칭으로 개발하여 프로그램 구성이 동일하나 주제별로 나누어져 있는 경우도 시리즈로 합하여 하나의 프로그램으로 간주하여 총 53 개의 어플리케이션이 분석 대상으로 수집되었다. 이 중 프로그램의 오류 등으로 분석에 적합하지 않은 어플리케이션 2 개를 제외한 총 51 개 어플리케이션을 최종 분석대 상으로 선정하였다. 연구대상 한국어 어휘학습용 어플리케이션의 교수방법과 학습유형을 구분한 결과, 51 개 어플리케이션 중 42 개 (82.4\%)가 발음중심 언어 교수방법에 근거하고 있었고, 나머지 9 개(17.6\%)는 총체적 언어 교수방법에 근거하고 있었다. 학습유형 의 경우 서술형 21 개(41.2\%), 놀이형 12 개(23.5\%), 문제풀이형 3 개(5.9\%), 복합형 15 개(29.4\%)로 나타났다(Table 1).

\section{2. 연구도구}

한국어 어휘학습용 어플리케이션의 내용분석을 위한 평정척도 는 Hyun 등[6], Yoo 등[25, 26]의 연구에서 사용된 유아용 어플리 케이션 척도를 한국어 어휘학습용 어플리케이션에 적합하게 평가 요소를 부분적으로 수정 및 보완하여 6 개의 하위 평가영역, 총 43 문항을 평가요소로 사용하였다(Table 2). 하위 평가영역은 사용의 용이성(9문항), 발달의 적합성(4문항), 교육적 가치(12문항), 오락 성(5문항), 기능성(6문항), 인터랙션 활용(7문항)으로 구분되며, 각 평가요소는 '전혀 그렇지 않다'를 1점, '매우 그렇다'를 4점으로 하 는 4점 Likert형 척도이며, 점수가 높을수록 해당 평가영역의 내용 이 우수한 것을 의미한다.

본 연구에서 사용된 한국어 어휘학습용 어플리케이션 평정척 도의 내용은 아동학 박사학위 소지자 3인으로부터 내용타당도를 검증받았다. 한국어 어휘학습용 어플리케이션 평정척도의 내적합 치도는 전체 평가요소 .944 , 사용의 용이성 .700 , 발달의 적합성 .708 , 교육적 가치 .826 , 오락성 .845, 기능성 .634, 인터랙션 활 용 .906으로 나타나 한국어 어휘학습용 어플리케이션 평정척도로 적합한 것으로 검증되었다.

\section{3. 연구절차 및 분석}

\section{1) 예비조사 및 평정자 훈련}

본 연구의 본조사를 실시하기 이전에 한국어 어휘학습용 어플 리케이션의 교수방법, 학습유형, 평가척도의 내용타당도를 확보하고 
Family and Environment Research

Table 1. List of Applications for Preschoolers' Korean Vocabulary Learning

\begin{tabular}{|c|c|c|c|c|c|}
\hline Application name & $\begin{array}{l}\text { Teaching } \\
\text { approach }\end{array}$ & $\begin{array}{l}\text { Type of } \\
\text { learning }\end{array}$ & Application name & $\begin{array}{l}\text { Teaching } \\
\text { approach }\end{array}$ & $\begin{array}{l}\text { Type of } \\
\text { learning }\end{array}$ \\
\hline Hangul ttarassgi & Phonics instruction & Descriptive & Smart hakseup byeeokgrim & Phonics instruction & Descriptive \\
\hline Eolini dongmul noli & Phonics instruction & Descriptive & Toktok I norae donghwa & Whole language & Descriptive \\
\hline Hangulilang nolja & Phonics instruction & Descriptive & Hangul tongtong & Phonics instruction & Play \\
\hline Agi hangul $\neg\llcorner\sqsubset$ [giyeok nieun digeut] & Phonics instruction & Descriptive & wooriai hangul ttegi & Phonics instruction & Combining \\
\hline Hangul saekchilnoli & Phonics instruction & Play & Popoya & Phonics instruction & Combining \\
\hline Jump baby & Phonics instruction & Descriptive & Sticker ganada & Phonics instruction & Combining \\
\hline Hangul a nolja & Phonics instruction & Descriptive & Saekchilnoli & Phonics instruction & Play \\
\hline Natmal card & Phonics instruction & Descriptive & Animal match & Whole language & Play \\
\hline Hangul puzzle & Phonics instruction & Play & Pilgigongju & Phonics instruction & Combining \\
\hline Ua Hangul & Phonics instruction & Descriptive & Hutos hangul wang & Phonics instruction & Descriptive \\
\hline Gateun card chatgi & Phonics instruction & Play & Hangul wang Cocomong & Whole language & Combining \\
\hline Kkambu hangul noli & Phonics instruction & Combining & Gicha $\neg\llcorner\sqsubset$ [giyeok nieun digeut] & Whole language & Descriptive \\
\hline Tori, Tomi wa hamkkehaneun Hangul noli & Phonics instruction & Play & Ganada noliteo & Phonics instruction & Descriptive \\
\hline Ssokssok hangulgongbu & Phonics instruction & Descriptive & Hangul jaram series & Whole language & Combining \\
\hline Hangul matchugi & Phonics instruction & Quiz & Alssongdalssong natmalCard & Phonics instruction & Combining \\
\hline Nooya hangulnoli & Whole language & Combining & Hangul & Phonics instruction & Descriptive \\
\hline Hangul grim quiz & Phonics instruction & Quiz & Kids school natmal card & Phonics instruction & Descriptive \\
\hline Malhaebwa PPororo & Whole language & Play & Klaevi alssongdalssong hangul noli & Phonics instruction & Combining \\
\hline Hangul card & Phonics instruction & Descriptive & Ssmyeonseobaewoyo & Phonics instruction & Descriptive \\
\hline Hangul meokgi & Phonics instruction & Play & Yoreotkehaebwayo & Phonics instruction & Play \\
\hline Mabeobcheonjamoon ua hangul sajeon & Phonics instruction & Descriptive & Hangul racing & Phonics instruction & Play \\
\hline Learn Korean & Phonics instruction & Descriptive & Hangul jaeum & Phonics instruction & Combining \\
\hline Dingdongdaeng hangul & Phonics instruction & Combining & Stoni grim daneo & Phonics instruction & Combining \\
\hline Eolini hangul wang & Phonics instruction & Descriptive & Hangul card & Phonics instruction & Combining \\
\hline Naneunsaenggak hangul & Whole language & Combining & Hangul noli & Phonics instruction & Play \\
\hline Donghwasok hangul noli & Whole language & Quiz & & & \\
\hline
\end{tabular}

평정자간 일치도를 확인하기 위해 예비조사를 실시하였다. 예비조사 를 위해 App Store와 Play Store에서 한국어 어휘학습용 어플리케이 션을 각 3 개씩 총 6 개 선정하고, 아동학 박사학위 소지자 3 인에 의해 예비분석을 실시하였다. 예비분석 결과 평정자간 의견이 일치하지 않은 경우에는 평정기준에 근거를 두고 평정자간 논의를 통해 합의 하는 과정을 거침으로써 본조사를 위한 평정자 훈련을 실시하였다.

\section{2) 본조사}

본 연구에서는 예비조사를 통해 한국어 어휘학습용 어플리케이 션의 교수방법, 학습유형, 평정척도의 내용타당도를 확보하고, 5 개의 어플리케이션에 대한 평정자간 일치도를 확인한 이후 본조사 대상인 총 51 개의 어플리케이션을 분석하였다. 본조사의 분석은 아동학 박사학위 소지자 3인에 의해 2014년 6월 9일부터 6월 27
일까지 3주간 실시되었고, 본조사의 어플리케이션에 대한 3인의 평정자 각각의 평정자간 일치도는 $90 \%, 88 \%, 80 \%$ 이었으며, 3 인 의 평정자간 평균 일치도(\%)는 $86 \%$ 이었다. 3 인의 평정자간 의견 이 일치하지 않은 경우에는 평정기준에 근거를 두고 평정자간 논 의를 통해 최종 평정을 실시하였다.

\section{3) 자료분석 및 통계처리}

수집된 자료는 SPSS ver. 18.0 (SPSS Inc., Chicago, IL, USA) 프로그램을 사용하여 분석하였으며, 한국어 어휘학습용 어플리케 이션의 교수방법, 학습유형, 평가점수의 일반적 경향은 기술통계 를 이용하여 분석하였다. 교수방법에 따른 평가점수의 차이는 $t-$ 검증, 학습유형에 따른 평가점수의 차이는 일원변량분석을 이용하 였으며, 사후검증으로 Scheffé 검증을 사용하였다. 
Table 2. Criteria of Applications for Preschoolers' Korean Vocabulary Learning

\begin{tabular}{|c|c|}
\hline Criteria & Item \\
\hline \multirow[t]{9}{*}{ Ease of use } & 1. Skills to operate the applications are within a child's ability. \\
\hline & 2. A child can operate the application independently after the first operation. \\
\hline & 3. Menu-key for operating is simple. \\
\hline & 4. Reading skill is not necessary for operating application. \\
\hline & 5. Application is easy to quit in the middle of operating. \\
\hline & 6. It is easy to go back to initial menu. \\
\hline & 7. Children can operate without help. \\
\hline & 8. Children can recognize their own mistakes as they happen. \\
\hline & 9. It is easy to go up to the next level. \\
\hline \multirow[t]{4}{*}{ Developmental appropriateness } & 1. It is appropriate for children's spoken language development. \\
\hline & 2. It is appropriate for children's written language development. \\
\hline & 3. Responses for children to operate are fast and accurate. \\
\hline & 4. The step and the configuration of the application are hierarchical. \\
\hline \multirow[t]{12}{*}{ Educational values } & 1. It presents one or more content area. \\
\hline & 2. Graphics are consistent with the educational intent of applications. \\
\hline & 3. Feedback is presented with meaningful graphics or sound. \\
\hline & 4. Spoken language is used. \\
\hline & 5. New content is presented each time. \\
\hline & 6. A challenge is possible in the proper range. \\
\hline & 7. Feedback enhances contents. \\
\hline & 8. Content are associated with the direct experiences of children. \\
\hline & 9. There is no gender discrimination in the content of the application. \\
\hline & 10. There is no racial bias in the content of the application. \\
\hline & 11. Applications have a strategy to extend learning. \\
\hline & 12. The amount of information is appropriate. \\
\hline \multirow[t]{5}{*}{ Amusement } & 1. Applications have a distinctive character are attractive. \\
\hline & 2. The sound and audio is attractive to children. \\
\hline & 3. Applications gradually raise difficulty levels. \\
\hline & 4. Children can select from a variety of levels to challenge. \\
\hline & 5. The application content are interesting to children. \\
\hline \multirow[t]{6}{*}{ Function } & 1. Applications have a language function. \\
\hline & 2. Child can save their work continuously. \\
\hline & 3. Applications have a variety of challenge levels that automatically adjust in different directions. \\
\hline & 4. Sounds are appropriate and can be adjusted. \\
\hline & 5. The use of applications are recorded accumulatively. \\
\hline & 6. Instructions for teachers and parents can be easily found and used. \\
\hline \multirow[t]{7}{*}{ Interaction } & 1. Application induces children's operational behavior. \\
\hline & 2. Application responds to operation by a child accurately. \\
\hline & 3. Application provides feedback immediately. \\
\hline & 4. Feedback can correct a child's errors. \\
\hline & 5. Feedback induces the child's proactive learning activity. \\
\hline & 6. The expression of a feedback attracts a child's attention. \\
\hline & 7. Icons are big and easy to choose from. \\
\hline
\end{tabular}




\section{연구결과 및 해석}

\section{1. 한국어 어휘학습용 어플리케이션 내용의 일반적 경향}

유아 대상 한국어 어휘학습용 어플리케이션 내용의 평가영역별 점수를 살펴본 결과(Table 3), 각 평가영역별 평균 점수는 사용의 용이성 28.14점, 발달의 적합성 11.39점, 교육적 가치 32.84점, 오락성 10.86점, 기능성 14.00점, 인터랙션 활용 16.78점으로 나 타나서 본 연구의 분석대상인 한국어 어휘학습용 어플리케이션은 전반적으로 각 평가영역별 점수가 양호한 것으로 확인되었다.

평가영역별로 문항 수에 차이가 있으므로 평가영역별 평균점수 를 문항 수로 나누어 문항별 평균을 살펴본 결과에 의하면, 평가영 역 중 사용의 용이성 점수가 3.13 점으로 가장 높았으며, 오락성 점 수가 2.17점으로 가장 낮게 나타났다.

\section{2. 교수방법에 따른 한국어 어휘학습용 어플리케이션 내용분석}

언어 교수방법에 따라 유아 대상 한국어 어휘학습용 어플리
케이션의 내용을 분석한 결과(Table 4), 인터랙션 활용의 경우에 만 교수방법에 따른 점수 차이가 유의한 것으로 나타났으며 $(t=-$ $2.027, p<.05)$, 다른 평가영역에서는 교수방법에 따른 차이가 유 의하지 않았다. 즉, 발음중심 교수방법에 근거한 어플리케이션의 경우 $(M=15.93, S D=6.78)$ 보다 총체적 교수방법에 근거한 어플리 케이션의 경우 $(M=20.78, S D=4.94)$ 에 인터랙션 기능의 활용 가능 성이 더 높은 것으로 나타났다.

\section{3. 학습유형에 따른 한국어 어휘학습용 어플리케이션 내용분석}

학습유형에 따라 유아 대상 한국어 어휘학습용 어플리케이션의 내용을 분석한 결과(Table 5), 전체( $F=13.912, p<.001)$ 평가점수와 발달의 적합성 $(F=3.435, p<.05)$, 교육적 가치 $(F=12.157, p<.001)$, 오락성 $(F=12.369, p<.001)$, 기능성 $(F=4.954, p<.01)$, 인터랙션 활 용 $(F=17.935, p<.001)$ 점수에서 유의한 차이가 있는 것으로 나타났 으며, 사용의 용이성에서는 유의한 차이가 나타나지 않았다.

학습유형에 따라 유의한 차이가 있는 것으로 나타난 발달의 적

Table 3. Evaluation Scores of Applications for Preschoolers' Korean Vocabulary Learning

\begin{tabular}{lcrrrrr}
\hline \multicolumn{1}{c}{ Criteria } & Total score & Min & Max & M & SD & M per item \\
\hline Ease of use & 36.00 & 19.00 & 35.00 & 28.14 & 4.36 & 3.13 \\
Developmental appropriateness & 16.00 & 6.00 & 16.00 & 11.39 & 2.91 & 2.85 \\
Educational values & 48.00 & 17.00 & 45.00 & 32.84 & 6.73 & 2.74 \\
Amusement & 20.00 & 5.00 & 20.00 & 10.86 & 4.18 & 2.17 \\
Function & 24.00 & 6.00 & 23.00 & 14.00 & 3.82 & 2.33 \\
Interaction & 28.00 & 7.00 & 27.00 & 16.78 & 6.71 & 2.40 \\
\hline Total & 172.00 & 72.00 & 159.00 & 114.02 & 23.93 & \\
\hline
\end{tabular}

Table 4. Evaluation Scores of Applications for Preschoolers' Korean Vocabulary Learning by Teaching Approach

\begin{tabular}{|c|c|c|c|c|}
\hline Criteria & Teaching approach & $M$ & $S D$ & $t$ \\
\hline \multirow[t]{2}{*}{ Ease of use } & Phonics instruction & 27.83 & 4.64 & -1.076 \\
\hline & Whole language & 29.56 & 2.46 & \\
\hline \multirow[t]{2}{*}{ Developmental appropriateness } & Phonics instruction & 11.21 & 2.95 & -.941 \\
\hline & Whole language & 12.22 & 2.73 & \\
\hline \multirow[t]{2}{*}{ Educational values } & Phonics instruction & 32.29 & 6.86 & -1.287 \\
\hline & Whole language & 35.44 & 5.70 & \\
\hline \multirow[t]{2}{*}{ Amusement } & Phonics instruction & 10.38 & 3.93 & -1.820 \\
\hline & Whole language & 13.11 & 4.81 & \\
\hline \multirow[t]{2}{*}{ Function } & Phonics instruction & 13.74 & 3.88 & -1.059 \\
\hline & Whole language & 15.22 & 3.49 & \\
\hline \multirow[t]{2}{*}{ Interaction } & Phonics instruction & 15.93 & 6.78 & -2.027 \\
\hline & Whole language & 20.78 & 4.94 & \\
\hline \multirow[t]{2}{*}{ Total } & Phonics instruction & 111.38 & 23.99 & -1.735 \\
\hline & Whole language & 126.33 & 20.52 & \\
\hline
\end{tabular}

$p<.05$ 
Family and Environment Research

Table 5. Evaluation Scores of Applications for Preschoolers' Korean Vocabulary Learning by Type of Learning

\begin{tabular}{|c|c|c|c|c|}
\hline Criteria & Type of learning & $M$ & $S D$ & $F$ \\
\hline \multirow[t]{4}{*}{ Ease of use } & Descriptive & 26.86 & 4.32 & 2.742 \\
\hline & Play & 27.17 & 5.34 & \\
\hline & Quiz & 28.33 & 4.62 & \\
\hline & Combining & 30.67 & 2.41 & \\
\hline Developmental & Descriptive & 10.19 & 2.64 & $3.435^{*}$ \\
\hline \multirow[t]{3}{*}{ appropriateness } & Play & 11.25 & 3.41 & \\
\hline & Quiz & 11.67 & 1.53 & \\
\hline & Combining & 13.13 & 2.33 & \\
\hline \multirow[t]{4}{*}{ Educational values } & Descriptive & 28.00 & 5.01 & \\
\hline & Play & 34.17 & 6.26 & \\
\hline & Quiz & 33.33 & 1.15 & \\
\hline & Combining & 38.47 & 4.91 & \\
\hline \multirow[t]{4}{*}{ Amusement } & Descriptive & 8.19 & 2.58 & $12.369^{\text {"Im }}$ \\
\hline & Play & 10.83 & 4.37 & \\
\hline & Quiz & 10.00 & 1.00 & \\
\hline & Combining & 14.80 & 3.19 & \\
\hline \multirow[t]{4}{*}{ Function } & Descriptive & 11.95 & 2.92 & $4.954^{* *}$ \\
\hline & Play & 15.33 & 3.93 & \\
\hline & Quiz & 12.67 & .58 & \\
\hline & Combining & 15.67 & 3.90 & \\
\hline \multirow[t]{4}{*}{ Interaction } & Descriptive & 11.38 & 3.88 & $17.935^{* *}$ \\
\hline & Play & 17.92 & 6.30 & \\
\hline & Quiz & 20.00 & 3.46 & \\
\hline & Combining & 22.80 & 4.54 & \\
\hline \multirow[t]{4}{*}{ Total } & Descriptive & 96.57 & 16.38 & 13.912 \\
\hline & Play & 117.17 & 22.64 & \\
\hline & Quiz & 116.00 & 9.54 & \\
\hline & Combining & 135.53 & 16.86 & \\
\hline
\end{tabular}

$p<.05, " p<.01, " * p<0.001$.

합성, 교육적 가치, 오락성, 기능성, 인터랙션 활용 평가영역의 경 우 Scheffé 검증을 통해 사후검증을 실시하였다(Table 6). 그 결과, 놀이형의 경우에는 전체 평가점수, 교육적 가치, 기능성, 인터랙션 활용 평가점수에서 서술형과 유의한 차이가 있는 것으로 나타났 고, 문제풀이형의 경우에는 인터랙션 활용 평가점수에서만 서술형 과 유의한 차이가 있는 것으로 나타났다. 복합형의 경우에는 전체 평가점수, 발달의 적합성, 교육적 가치, 기능성, 인터랙션 활용 평 가점수에서는 서술형과, 오락성에서는 서술형 및 놀이형과 유의한 차이가 있는 것으로 나타났다.

\section{논의 및 결론}

Table 6. Evaluation Scores of Applications for Preschoolers' Korean Vocabulary Learning by Type of Learning (Scheffés Test)

\begin{tabular}{llrrc}
\hline \multicolumn{1}{c}{ Criteria } & Type of learning & Play & Quiz & Combining \\
\hline Developmental & Descriptive & -1.060 & -1.476 & $-2.943^{*}$ \\
appropriateness & Play & & -.417 & -1.883 \\
& Quiz & & & -1.467 \\
Educational values & Descriptive & $-6.167^{*}$ & -5.333 & $-10.467^{*}$ \\
& Play & & .833 & -4.300 \\
& Quiz & & & -5.133 \\
Amusement & Descriptive & -2.643 & -1.810 & $-6.610^{*}$ \\
& Play & & .833 & $-3.967^{*}$ \\
\hline \multirow{2}{*}{ Function } & Quiz & & & -4.800 \\
& Descriptive & $-3.881^{*}$ & -.714 & $-3.714^{*}$ \\
& Play & & 3.167 & .167 \\
Interaction & Quiz & & & 3.000 \\
& Descriptive & $-6.536^{*}$ & $-8.619^{*}$ & $-11.419^{*}$ \\
\hline Total & Play & & -2.083 & -4.883 \\
& Quiz & & & -2.800 \\
& Descriptive & $-20.595^{*}$ & -19.429 & $-38.962^{*}$ \\
& Play & & 1.167 & -18.367 \\
\hline
\end{tabular}

$p<.05$

본 연구에서는 유아 대상 한국어 어휘학습용 어플리케이션의 내 용분석을 위해 51 개의 태블릿 PC 어플리케이션을 분석대상으로 선 정하고, 이들의 일반적 경향과 교수방법 및 학습유형에 따른 내용분 석의 차이에 대해 살펴보았다. 그 결과 다음과 같은 결론을 도출하 였다.

첫째, 본 연구의 분석대상인 한국어 어휘학습용 어플리케이션 은 각 평가영역별 점수는 전반적으로 양호한 것으로 확인되었다. 평가영역별 총점을 기준으로 살펴볼 때 사용의 용이성, 발달의 적 합성, 교육적 가치, 오락성, 기능성, 인터랙션 활용 영역에서 전반 적으로 양호한 편이었으나 우수한 수준은 아니었다. 일부 어플리 케이션은 평가영역별 평균점수를 충족시키지 못하는 낮은 점수를 획득한 경우도 있어서 분석대상 어플리케이션 간에 평가점수의 격 차가 큰 것으로 나타났다. 평가영역의 문항별 평균점수를 비교한 결과, 평가영역 중 사용의 용이성 점수가 가장 높았으며, 오락성 점수가 가장 낮게 나타났다. 사용의 용이성 점수가 가장 높게 나타 난 것은 선행연구와 일치하는 결과[6]로 이는 분석대상 한국어 어 휘학습용 어플리케이션이 유아가 혼자 사용하기에 어렵지 않음을 의미한다. 오락성 점수가 가장 낮게 나타난 것은 선행연구결과[6] 와 일치하지 않는데, 이는 선행연구에서는 단어게임, 즉 게임형 어 플리케이션만을 대상으로 하여 오락성 점수가 가장 낮지 않았으 
나, 본 연구에서는 게임형이 포함된 놀이형 이외에도 서술형, 문제 풀이형 등의 다양한 학습유형이 분석대상에 포함되어 오락성 점수 가 상대적으로 낮게 나온 것으로 해석된다.

둘째, 유아 대상 한국어 어휘학습용 어플리케이션의 내용을 언 어 교수방법에 따라 분석한 결과, 교수방법에 따라 인터랙션 활용 평가점수가 다르게 나타났다. 즉, 발음중심 교수방법에 근거한 어 플리케이션의 경우보다 총체적 교수방법에 근거한 어플리케이션 의 경우에 인터랙션 기능의 활용 가능성이 더 높은 것으로 나타나 서 총체적 교수방법에 근거한 어플리케이션이 유아의 조작행동을 더 유도하고, 피드백이 더 즉각적이었다. 이러한 결과는 유아를 대 상으로 한국어 어휘를 가르치는데 있어서 발음중심 교수방법에 근 거를 둔 어플리케이션보다는 총체적 교수방법에 근거를 둔 어플리 케이션을 이용하는 것이 더 효과적일 수 있음을 보여준다. 자모체 계, 글자와 말소리 대응, 철자법 등의 학습을 강조함으로써 문자 언어발달에 필요한 기초적인 지식과 기술을 가르치는 발음중심 교 수방법보다는 맥락에서의 의미를 강조하여 의사소통과 의미 이해 를 목적으로 하는 총체적 교수방법이 스마트교육에서도 더 효과적 임을 알 수 있다. 이처럼 언어 교수방법에 따라 한국어 어휘학습용 어플리케이션을 분석한 선행연구는 거의 찾아 볼 수 없으므로 후 속연구를 통해 본 연구의 결과와 일관된 결과가 나타나는지 확인 할 필요가 있다.

셋째, 학습유형에 따라 유아 대상 한국어 어휘학습용 어플리 케이션의 내용을 분석한 결과, 학습유형에 따라 전체 평가점수와 발달의 적합성, 교육적 가치, 오락성, 기능성, 인터랙션 활용 평 가점수가 다르게 나타났다. 놀이형의 경우에는 전체 평가점수, 교육적 가치, 기능성, 인터랙션 활용 평가영역에서 서술형보다 점수가 더 높은 것으로 나타났고, 문제풀이형의 경우에는 인터 랙션 활용 평가영역에서만 서술형보다 점수가 더 높은 것으로 나 타났다. 복합형의 경우에는 전체 평가점수, 발달의 적합성, 교육 적 가치, 기능성, 인터랙션 활용 평가영역에서는 서술형보다, 오 락성에서는 서술형 및 놀이형보다 점수가 더 높은 것으로 나타났 다. 이러한 결과는 유아교육용 어플리케이션을 콘텐츠 유형에 따 라 분석한 선행연구[26]의 경우 학습유형 구분이 본 연구와 달라 서 직접적인 비교는 불가능하지만, 교육성 평가영역에서 차이가 나타난 점은 본 연구의 결과와 일맥상통한다고 볼 수 있다. 선행 연구에서는 복합형을 포함시키지 않았으나 본 연구에서는 복합 형을 포함시켜 살펴보았는데, 그 결과 사용의 용이성을 제외한 다른 평가영역 점수에서 복합형이 서술형에 비해 점수가 더 높게 나타났다. 이는 분석대상 어플리케이션 중 대부분의 복합형 어플 리케이션이 서술형과 놀이형, 또는 서술형과 문제풀이형이 결합
된 형태이므로 한국어 어휘학습을 위한 어플리케이션의 경우 단 일한 학습유형보다는 복합적인 학습유형의 어플리케이션이 효과 적임을 확인시켜주는 결과이다. 따라서 향후 유아의 한국어 어휘 학습용 어플리케이션을 개발할 경우 복합적인 학습유형의 어플 리케이션을 개발할 필요가 있다. 이처럼 복합적인 학습유형의 어 플리케이션을 유아가 활용할 경우 한국어 어휘학습에 보다 흥미 를 가지고 적극적인 참여를 유도할 것으로 예상된다. 복합적인 학습유형의 어플리케이션을 활용할 경우 인지부하이론의 관점을 고려할 필요가 있다. 인지부하란 특정과제에서 요구되는 지적 노 력의 양을 의미하며, 인지부하이론에서는 인간의 기억을 용량이 제한된 작업기억과 용량이 무한한 장기기억으로 구성되어 있다 고 가정하므로 인지부하이론은 유아를 대상으로 한 멀티미디어 콘텐츠를 설계할 때 유용한 시사점을 제공한다[9]. 본 연구의 결 과에서 유아의 어휘학습용 어플리케이션의 학습유형이 복합형인 경우 평가점수가 더 높게 나타나긴 하였으나, 복합형의 경우 유 아기의 인지발달 특성에 적합한 수준에서 어플리케이션이 설계 되어야 한다는 점에 유의할 필요가 있다. 즉, 유아는 학습 자료 에 대한 경험 정도가 낮기 때문에 작업기억의 인지적 과부하를 최대한 방지할 수 있는 어플리케이션을 설계하여 제공할 필요가 있음을 확인할 수 있다.

본 연구는 언어 교수방법을 발음중심과 총체적 교수방법으로만 구분하여 살펴보았다는 점, 학습유형 중 문제풀이형의 분석대상 어플리케이션의 수가 적다는 점에서 연구의 제한점을 찾을 수 있 다. 이러한 제한점에도 불구하고, 본 연구는 선행연구에서 주로 유 아교육용 어플리케이션에 대한 전반적인 분석을 실시한 것과 차별 적으로, 유아 대상 한국어 어휘학습용 어플리케이션에 초점을 맞 추어 분석을 시도했다는 점에서 연구의 의의를 찾을 수 있다.

유아의 한글 낱자 지식과 자소-음소대응규칙 지식이 연령이 증가함에 따라 발달하며 이러한 능력이 유아의 읽기발달에 직접 적인 영향을 미친다는 점 $[1,4,16]$, 어휘학습에 스마트기기를 활 용하는 것이 효과적이라는 점[19, 21, 22]을 고려해 볼 때, 어휘 발달에 문제가 있는 일반가정 유아나 다문화가정 유아가 한국어 를 능숙하게 사용하여 초등학교생활에 잘 적응하기 위해서는 유 아기에 한국어 능력 향상을 위해 태블릿 $\mathrm{PC}$ 용 어플리케이션을 활 용한 조기 개입의 필요성을 예측해 볼 수 있다. 총체적 언어 교수 방법과 복합형 학습유형의 어플리케이션이 유아의 어휘학습에 효 과적이라는 본 연구의 결과는 언어발달, 특히 어휘발달이 또래에 비해 뒤떨어지는 유아와 다문화가정 유아의 어휘발달을 촉진시키 는데 태블릿 $\mathrm{PC}$ 용 어플리케이션이 보조적인 도구로 활용될 수 있 음을 보여준다. 예를 들어, 다문화가정 유아의 경우 어머니의 한 
국어 능력이 뒤떨어져 자녀와 의사소통에 어려움이 있고, 이로 인 해 자녀의 한국어 발달이 지체되는 경향을 보인다. 이처럼 어머 니에 의한 한국어 자극이 충분하지 못하여 유아의 언어발달에 문 제가 발생할 경우 한국어가 능숙한 또래나 교사 등으로부터 한국 어 자극을 제공받는 것이 효과적이지만, 이러한 직접적 상호작용 이 제공되기 어려울 경우 태블릿 $\mathrm{PC}$ 용 어플리케이션이라는 도구 를 활용하여 한국어 어휘학습에 도움을 제공함으로써 다문화가정 유아의 한국어 발달이 촉진될 수 있다. 이 연구에서 유아를 대상 으로 제공되고 있는 기존의 태블릿 $\mathrm{PC}$ 어플리케이션의 내용과 특 성을 분석함으로써 기존에 개발된 어플리케이션이 유아의 한국어 어휘능력을 향상시키는데 적합한지를 확인하였고, 그 결과는 후 속연구에서 체계적인 한국어 어휘학습용 어플리케이션을 개발하 는데 기초자료로 사용될 수 있다는 점에서 연구의 의의를 찾을 수 있다.

후속연구를 위한 제언은 다음과 같다. 첫째, 선행연구[27]에서 유아용 인기 교육 어플리케이션에 대해 분석한 터치 제스처와 모 션 제스처의 특성을 한국어 어휘학습용 어플리케이션 분석에도 적 용해보는 후속연구가 필요하다. 둘째, 선행연구[6]에서 단어게임 용 어플리케이션에 한정하여 한글과 영어 어플리케이션의 차이를 분석하였는데, 후속연구에서는 게임형에만 한정하지 않고 다양한 학습유형의 어휘학습용 어플리케이션을 대상으로 한글과 영어 어 플리케이션의 차이를 비교 분석할 필요가 있다. 마지막으로 본 연 구에서는 실제 유아를 대상으로 분석대상 어플리케이션을 실제 활 용해보도록 하지 않고, 아동학 전문가의 입장에서 평가하였기 때 문에 후속연구에서는 실제 유아를 대상으로 어휘학습용 어플리케 이션을 활용하도록 하여 실제적 효과를 검증해볼 필요가 있다. 이 를 통해 어휘학습용 어플리케이션의 구체적인 활용방안을 분석해 볼 필요가 있다. 평가 결과 우수한 것으로 나타난 한국어 어휘학습 용 어플리케이션의 경우 실제 유아를 대상으로 일정 기간 동안 실 행하도록 한 후 그 효과를 검증하는 후속연구 역시 필요하다.

\section{Declaration of Conflicting Interests}

The author declared that she had no conflicts of interests with respect to her authorship or the publication of this article.

\section{Acknowledgements}

This research was supported by Seokyeong University in 2012.

\section{References}

1. Ahn, S. W., \& Heo, M. J. (2011). A study of knowledge of letter names and phoneme-grapheme correspondence for Korean kindergarten children. The Journal of Special Children Education, 13(2), 267-287.

2. Chen, X. B. (2013). Tablets for informal language learning: Student usage and attitudes. Language Learning \& Technology, 17(1), 20-36.

3. Cho, S. K. (2009). Smartphones used for foreign language learning. Multimedia-Assisted Language Learning, 12(3), 211-228.

4. Foy, J. G., \& Mann, V. (2006). Changes in letter sound knowledge are associated with development of phonological awareness in pre-school children. Journal of Research in Reading, 29(2), 143-161. http://dx.doi. org/10.1111/j.1467-9817.2006.00279.x

5. Han, Y. M., Kim, H. S., Kwon, H. K., \&t Yang, Y. S. (2010). Understanding of young children's language education. Seoul: Hakjisa.

6. Hyun, E. J., Yeon, H. M., Jang, J. Y., \& Lee, E. Y. (2013). Contents analysis of vocabulary learning game application on smart-phone and tablet PC for young children's language learning. Journal of the Korea Contents Association, 13(11), 551-561. http://dx.doi.org/10.5392/ JKCA.2013.13.11.551

7. Jung, S. J., Lim, G., Ko, Y. J., Sim, H. A., \&t Kim, K. Y. (2010). The analysis of trends in smart phone applications for education and suggestions for improved educational use. Journal of Digital Contents Society, 11(2), 203-216.

8. Kang, Y. J., Han, W. C., \& Cho, T. Y. (2011). Implementation of a learning app using an android smart phone. Paper presented at the 44th Summer Conference of the Korean Society of Computer and Information, Korea, 419-420.

9. Kim, E. J., Park, S. D., \& Kim, K. C. (2011). The analysis of smart phone application for early childhood based on cognitive theory. Journal of Korea Game Society, 11(4), 163-174.

$10 \mathrm{Kim}$, J. H., \& Lim, H. S. (2011). Smart learning using web and smart devices: Blended collaborative learning system. Conference Proceedings of the Korean Association of Computer Education, 15(2), 81-84.

11. Kukulska-Hulme, A., \& Shield, L. (2008). An overview of mobile assisted language learning: From content delivery to supported collaboration and interaction. ReCALL, 20(3), 271-289. http://dx.doi.org/10.1017/ S0958344008000335

12. Lee, J. S., \& Choi, J. H. (2012). Implementation of application for vocabulary learning through analysis of users needs using smart phone. The Journal of Korean Association of Computer Education, 15(1), 43-53.

13. Lee, J. Y. (2011). The perception of parent on smart phone application for early childhood education (Unpublished master's thesis). Kyung 
Hee University, Seoul, Korea.

14. Lee, N. 0. (2005). The preference of children and parent on the online learning contents and evaluation of parent (Unpublished master's thesis). Sookmyung Women's University, Seoul, Korea.

15. Lee, S. W. (2014, March 4). 2013 Global tablet PC sales increase. iT DongA. Retrieved November 25, 2014, from http://it.donga. $\mathrm{com} / 17525 /$

16. Molfese, V. J., Modglin, A. A., Beswick, J. L., Neamon, J. D., Berg, S. A., Berg, C. J., et al. (2006). Letter knowledge, phonological processing, and print knowledge: Skill development in nonreading preschool children. Journal of Learning Disabilities, 39(4), 296-305. http://dx.doi.org/10.1177 /00222194060390040401

17. Oh, H. Y., \& Min, B. W. (2010). App design style and usability analysis for smart phone application: Focusing on the iPhone and Appstore. Journal of the Korea Contents Association, 10(12), 129-136. http:// dx.doi.org/10.5392/ JKCA.2010.10.12.129

18. Park, J. C. (2013). Design and development of mobile-based application for learning Hangeul(Korean Alphabet) (Unpublished master's thesis). Sangmyung University, Seoul, Korea.

19. Reinders, H. (2010). Twenty ideas for using mobile phones in the language classroom. English Teaching Forum, 46(3), 20-25.

20. Sim, Y. J. (2013). The effect of the Korean vocabulary learning using mobile game application (Unpublished master's thesis). Ewha Womans University, Seoul, Korea.

21. Stockwell, G. (2007). Vocabulary on the move: Investigating an intelligent mobile phone-based vocabulary tutor. Computer Assisted Language Learning, 20(4), 365-383. http://dx.doi. org/10.1080/09588220701745817

22. Stockwell, G. (2010). Using mobile phones for vocabulary activities: Examining the effect of the platform. Language Learning \& Technology, 14(2), 95-110.

23. Upadhyay, N. (2006). M-learning: A new paradigm in education. International Journal of Instructional Technology and Distance Learning, 3(2), 31-34.

24. Van Orden, S. (2006). Using a tablet PC in the German classroom to enliven teacher input. Die Unterrichtspraxis/Teaching German, 39(2), 109-112. http://dx.doi.org/10.1111/j.1756-1221.2006.tb00022.x

25. Yoo, K. J., Jung, S. N., Kim, M. K., \& Yang, A. S. (2008). Internet contents evaluation for early childhood education and case analysis by contents type. The Journal of Korea Open Association for Early Childhood Education, 13(5), 191-216.

26. Yoo, K. J., Kim, M. K., \& Kim, E. A. (2012). An analysis of contents and interactions for the educational application on smart-phone and tablet PC. The Journal of Korea Open Association for Early Childhood Education, 17(1), 169-194.

27. Yoon, H. M. (2014). Types and features of popular educational applications for young children: Focusing on Android app store. Paper presented at the Conference Proceedings of the $\mathrm{HCl}$ Society of Korea 481-484. 